\title{
LI. On the amount of radium emanation in the atmosphere near the earth's surface
}

\author{
A.S. Eve D.Sc.
}

To cite this article: A.S. Eve D.Sc. (1908) LI. On the amount of radium emanation in the atmosphere near the earth's surface , Philosophical Magazine Series 6, 16:94, 622-632, DOI: $10.1080 / 14786441008636540$

To link to this article: http://dx.doi.org/10.1080/14786441008636540

曲 Published online: 21 Apr 2009.

Submit your article to this journal $₫$

Џ Article views: 3

Q View related articles $\square$

Citing articles: 1 View citing articles 5 
LI. On the Amount of Radium Emanation in the Atmosphere near the Earth's Surface. By A. S. Eve, D.Sc., Associate Projessor of Mathematics, McGill University, Montreal*

T $\mathrm{N}$ a previous paper published in this Magazine (December 1907) a preliminary account was given of determinations of the amount of radium emanation present in the atmosphere. In the present communication the results are given of experiments, continued at intervals throughout a year, which not only determine the amount with greater accuracy, but also throw some light on the effect of meteorological conditions in causing variations in that amount.

In order to save reference a brief summary of the previous paper is here given. The experiments were made at Montreal, in the Chemistry Building of McGill University, in a room about fifty feet above the ground. The air, drawn from outside through cotton-wool, was passed through three glass tubes containing charcoal prepared from the shells of coconuts. The air-current was continued for 2.7 days, at a speed of $6.7 \mathrm{~cm} . .^{3} / \mathrm{sec}$. , so that $1.56 \mathrm{~m}^{3}$ of air passed through the tubes, two of which were in parallel + and the third in series with them. The tubes were then successively heated over two Bunsen flames, so that the gases absorbed by the charcoal were expelled, and these were collected over water and introduced into a silvered glass electroscope, which had previously been partially exhausted by a filter pump. The movements of the leaf of the electroscope were measured in the usual way with a microscope.

A solution of radium bromide, containing $1.57 \times 10^{-9} \mathrm{gram}$ of pure radium, taken from a standard solution prepared by Boltwood $\ddagger$, Levin, and the writer, was then introduced into a flask. Air was bubbled through this solution, dried by passing through two flasks of concentrated sulphuric acid, and passed at the same rate for the same time and through the same charcoal as before. The tubes were heated, and the freed gases were collected and tested for radium emanation. It was found that, at the above-named speed, about twenty per cent. of the emanation given off' by the solution was in this manner introduced into the electroscope. This percentage was found to be a function of the speed of the air-current, but within wide limits it appeared to be inde-

* Communicated by the Author.

+ It is better not to place tubes in parallel as the resistances to the air-current are often unequal and inconstant.

$\ddagger$ American Journal of Science, vol. xxii. July 1906. 
pendent of the total strength of the solution employed, ranging from $1.57 \times 10^{-7}$ to $10^{-10}$ gram of radium.

Thus the emanation from $1.56 \mathrm{~m} .^{3}$ of air gave an electroscope reading of 0.125 division a minute, and that from $1.57 \times 10^{-9}$ grm. of radium gave 0.98 . Hence it was reasoned that one cubic metre of air contained the emanation which would be in equilibrium with $\frac{0.125}{1.56^{\circ}} \times \frac{1.57 \times 10^{-9}}{0.98}$ or
$127 \times 10^{-12}$ gram of radium.

The quantities of charcoal employed were varied and experiments were made at intervals during several weeks. The lowest value found was stated to be $24 \times 10^{-12}$, and the highest $127 \times 10^{-12}$, with a probable average value of $80 \times 10^{-12}$ gram.

There is, however, a somewhat subtle error in the above method of reasoning. If the speed of the air-current through the tubes is varied, the percentage amount of emanation absorbed by the charcoal is a function of the speed. The exact relations between these quantities have not, however, as yet been determined in the case of radium emanation. When air is drawn for a given time from the atmosphere through the tubes, it is clear that, on varying the speed, the greater the amount of air, the greater is the amount of emanation passing to the charcoal. But when using the standard solution of radium, the amount of emanation passing: therefrom to the charcoal in a given time is entirely independent of the speed of the air-current, although the percentage amount absorbed is dependent on the speed in both cases. It will be seen then that the method of calculation given above is not quite correct, and it should be replaced by the following:-

I. Let $1 \mathrm{grm}$. of radium produce $m$ grms. of emanation per second, and let M gms. of emanation be in equilibrium with $1 \mathrm{grm}$. of radium, so that

$$
\mathrm{M}=\int_{0}^{\infty} m e^{-\lambda t} d t=\frac{m}{\lambda} .
$$

II. Let the amount of radium in the standard solution be $R^{\prime}$, and suppose that initially any accumulation of emanation has been removed by boiling or by an air-current. The amount of emanation given off is $m \mathrm{R}^{\prime}$ grm. per second, so that if at the end of the experiment, after absorption, heating, and collection, $\mathrm{Y}^{\prime}$ is the maximum electroscope reading, in divisions per minute, due to the emanation from the solution, we have

$$
\mathrm{Y}^{\prime}=\int_{0}^{\mathrm{T}} k m \mathrm{R}^{\prime} e^{-\lambda t} d t=k m \mathrm{R}^{\prime} \frac{1-e^{-\lambda \mathrm{T}}}{\lambda} . .
$$


Here $\mathrm{T}$ is the time during which the air-current passes through the charcoal, and $k$ is a constant depending on the electroscope calibration and on the percentage absorption of the charcoal.

III. In the case of air drawn from outside through the charcoal, let $\mathrm{X}$ equal the average number of grams of emanation present in one cubic metre of the atmosphere during the experiment, and let $v$ be the volume, in cubic metres, of air passing to the charcoal every second. If $\mathrm{Y}$ is the maximum reading of the electroscope in divisions per minute, after collection, heating, and introduction in the electroscope, we find

$$
\begin{aligned}
\mathrm{Y} & =\int_{0}^{\mathrm{T}} k v \mathrm{X} e^{-\lambda t} d t \\
& =k v \mathrm{X} \frac{1-e^{-\lambda \mathrm{T}}}{\lambda}=k \mathrm{VX}\left(\frac{1-e^{-\lambda \mathrm{T}}}{\lambda \mathrm{T}}\right), . .
\end{aligned}
$$

where $k$ is the same constant as before, and $v \mathrm{~T}=\mathrm{V}$ is the total number of cubic metres of air passing to the charcoal in time $\mathrm{T}$.

But $\mathrm{X}=\mathrm{RM}=\mathrm{R} \frac{m}{\lambda}$, where $\mathrm{R}$ is the amount of pure raclium which would be in equilibrium with the emanation actually present in each cubie matre of the atmosphtere at the time and place of the experiment.

So that

$$
\mathrm{Y}=k \mathrm{~V} \frac{\mathrm{R} m}{\lambda \mathrm{T}} \frac{1-e^{-\lambda \mathrm{T}}}{\lambda} .
$$

Comparing (1) and (2)

$$
\mathrm{Y}^{\prime} / \mathrm{Y}=\mathrm{R}^{\prime} \lambda \mathrm{T} / \mathrm{RV}
$$

and finally we have

$$
\mathrm{R}=\mathrm{R}^{\prime} \frac{\mathrm{Y}}{\mathrm{Y}^{\prime}} \frac{\lambda \mathrm{T}}{\mathrm{V}} \cdot \cdot \cdot \cdot \cdot \cdot \cdot \cdot \cdot
$$

This formula will first be applied to the experiments given in the previously published paper (Dec. 1907).

Case 1.-Eight cubic metres of air were passed in $3 \cdot 7$ days through three iron tubes in parallel, each containing 220 grams of coconut charcoal. From the three tubes 15 litres of gas were driven off by heat, collected and then passed very slowly through three small glass tubes in series, each containing 7 grams of charcoal. In turn these were heated, and the gases driven off were collected over water and inserted in the electroscope. 
Emanation in the Atmosphere near Earth's Surface. 625

A standard solution, containing $10^{-9} \mathrm{grm}$. of radium, was then placed in a flask, the accumulated emanation was removed, and air was passed through the solution to the three iron tubes containing charcoal, and the experiment was in all other respects repeated as before.

Then

$$
\begin{aligned}
R^{\prime} & =10^{-9} \mathrm{grm} . \\
\mathrm{Y} & =0 \cdot 40, \quad \mathrm{Y}^{\prime}=1 \cdot 45 \mathrm{D} / \mathrm{m} . \\
\mathrm{V} & =8 \mathrm{~m}^{3} . \\
\mathrm{T} & =3 \cdot 7 \text { days }=3 \cdot 19 \times 10^{5} \text { secs. } \\
\lambda & =2 \cdot 16 \times 10^{-6} \text { and } \lambda \mathrm{T}=0 \cdot 69 .
\end{aligned}
$$

and hence

$$
\mathrm{R}=10^{-9} \cdot 1 \cdot 45 \cdot \frac{0 \cdot 69}{8}=23 \cdot 9 \times 10^{-12} \text {. }
$$

This replaces the value $35 \times 10^{-12}$ given in the previous paper.

Case 2.- The mean of seven observations, made in July and August 1907 gave $\mathrm{Y}=0.112, \mathrm{Y}^{\prime}=0.98 \mathrm{D} / \mathrm{m}$, $\mathrm{R}^{\prime}=1.57 \times 10^{-9} \mathrm{gm} ., \mathrm{V}=1.56 \mathrm{~m}^{3}, \quad \mathrm{~T}=2.7 \quad$ days $=2.32 \times$ $10^{5}$ secs.

Hence $R=57 \cdot 4 \times 10^{-12}$, in place of $127 \times 10^{-12} \mathrm{grm}$. as given in the previous paper.

Case 3.-A typical example is given for a result subsequent to 11 th Nov. 1907, namely, that of 26 th Dec. 1907.

$$
\begin{aligned}
\mathrm{R}^{\prime} & =1.57 \times 10^{-9} \mathrm{grm} . \\
\mathrm{Y} & =0.39, \quad \mathrm{Y}^{\prime}=2.70 \mathrm{D} / \mathrm{m} . \\
\mathrm{V} & =1.35 \mathrm{~m}^{3} . \\
\mathrm{T} & =2.32 \times 10^{5} \text { secs. } \\
\lambda^{\prime} \mathrm{T} & =0.50 .
\end{aligned}
$$

Hence $\mathrm{R}=84 \cdot 2 \times 10^{-12} \mathrm{grm}$. In every case the value of $\mathrm{Y}^{\prime}$ is given after deducting that due to the emanation in the air passing to the charcoal.

It is unnecessary to give further examples of the method of calculation.

The experiments were continued for almost a year in order to ascertain the relation existing between the amount of emanation in the air and the meteorological conditions existing during the time of the experiment. As the air was passed through the charcoal for a little more than two and a half days, it is clear that the amount of emanation measured is not dependent on merely local conditions. The radium emanation decays to half value in about 3.8 days. With a wind velocity of 20 miles an hour, the emanation collected

$$
\text { Plil. Mag. S.6. Vol. 16. No. 94. Oct. 1908. } 2 \text { T }
$$


at the end of an experiment may have travelled 1300 miles since the experiment began: and some of the emanation may have left the radium in the ground, or sea, any time during about a month previous, although the greater proportion must have been of much more recent origin. It is therefore possible to connect only the most strongly marked differences, in excess or defect, of the amount of emanation present, with very clearly defined weather conditions. Moreover, the amount of emanation collected is so small that the effect even in a good electroscope is less than the natural leak, so that too much importance must not be attached to any one reading.

The results obtained are given in the Table which follows (pp. 628-9) and they may be divided into two series, separated by a double line. For, on the 12th November, 1907, there was an abrupt breakdown in the electroscope due to a thin deposit of black dust on the sulphur bead insulation, possibly due to smoke or very fine dust from the charcoal. The whole apparatus was reconstructed of fresh material after this accident, and the natural leak and calibration of the electroscope were therefore altered. The two series give results in satisfactory agreement. In the second column of the table is given the sum of the three readings obtained after testing the emanation expelled by heat from the charcoal in each of the three glass tuhes. The figures in the third column are obtained by subtracting from those in the second column the average electroscope reading deduced from a number of "rest" experiments. A "rest" experiment consisted of testing the gases from the three tubes after $2 \cdot 7$ days' rest, during which no air was drawn through the contained charcoal. Before November 12th the "rest" experiments gave, in divisions a minute, $\cdot 251, \cdot 221, \cdot 243, \cdot 233, \cdot 276, \cdot 243, \cdot 277$, with a mean value $\cdot 250$. This is larger than three times the natural leak of the electroscope, which was $3 \times \cdot 065$, or $\cdot 19.5$. I have never found the glass tubes, containing the charcoal, entirely free from emanation, some of which probably entered the tubes during cooling from the previous heating, and some was perhaps due to minute traces of radium in the glass or the charcoal. The amount was fairly constant, and too small to interfere with the main issue under investigation. A very slow current of air through the tubes gave rise to about the same electroscope readings as a "rest" experiment.

After November 12th the "rest" experiments gave 435 , $\cdot 456, \cdot 432, \cdot 449$, with a mean of 450 divisions a minute, whilst three times the natural leak was $3 \times \cdot 123$ divisions a minute. 
The tbird column in the table gives the amount of radium which would be required to supply the emanation to one cubic metre of the atmosphere at the place and during the time of the observation on the supposition that the emanation is in equilibrium with the amount of radium stated.

I venture to call this the radium equivalent per cubic metre.

The remaining columns give the approximate means of the temperature in degrees Fahrenheit, the barometric pressure in inches, and the wind direction, during the time of the experiments. Remaris have been added to indicate the weather conditions, when well defined. The figures and remarks are deduced from notes made at the time, from the weather reports of the McGill University Observatory, issued by Professor C. H. McLeod, and from the weather maps issued daily by the United States Department of Agriculture.

\section{Discussion of Results.}

In the first place it will be seen that temperature has little or no appreciable direct effect on the amount of emanation in the atmosphere near the earth's surface. The results for July and August with a mean temperature of $65^{\circ} \mathrm{F}$. are not very different from those made in the month of January with a mean temperature of $12^{\circ} \mathrm{F}$.

Again, during the month of March there was, at Montreal, an average depth of snow between two and three feet, and yet the radium equivalent, $45 \cdot 5 \times 10^{-12}$, was but little less than that for April, $51.5 \times 10^{-12}$, after the snow had melted. These results agree with the observations of Rutherford and Allen, that the active deposit collected from the atmosphere varied little in magnitude between summer and winter, even when the wind blew from cold regions deeply covered with snow. This fact suggests that the radium emanation escapes from considerable depths in the ground.

It may be noted, however, that in the wiater 1907-8 the snow preceded any severe frosts and so protected the earth that the ground was scarcely frozen.

It may be stated generally that, so far as these experiments go, they indicate that a well-defined cyclone, accompanied by heavy rain or a quick thaw of snow, gives maximum values to the radium equivalent. On the other hand, anticyclones, with dry weather, and, in winter, very low temperatures, give minimum values. 
If curves are plotted which show the variations of barometer pressure and radium equivalent, it is found that the fluctuations are not markedly synchronons, and that a connexion can only be established when the changes of pressure are exceptionally large. The reason for this has already been indicated, and depends upon the slow rate of decay of radium emanation and the necessarily long period of each experiment.

SERIES 1.

\begin{tabular}{|c|c|c|c|c|c|c|c|c|}
\hline Date. & $\begin{array}{c}\text { Electro- } \\
\text { scope } \\
\text { reading. }\end{array}$ & $\begin{array}{l}\text { Less } \\
\text { "rest" } \\
\text { value. }\end{array}$ & $\underset{\text { grms. } \times 10^{-12}}{\text { Radium }}$ & $\begin{array}{l}\text { Temp. } \\
\text { Fahr }\end{array}$ & $\begin{array}{l}\text { Bar. } \\
\text { ins. }\end{array}$ & Wind. & $\begin{array}{l}\text { Rain } \\
\text { ins. }\end{array}$ & Remarks. \\
\hline $\begin{array}{c}1907 \\
\text { July } 13\end{array}$ & $\cdot 331$ & .081 & $41.7 i$ & & & & & Shallow cyclones \\
\hline 19 & $\cdot 383$ & $\cdot 133$ & $68 \cdot 6$ & 70 & $29 \cdot 8$ & S.w. & $\ldots$ & \& thunderstorms. \\
\hline 25 & 335 & .085 & $43 \cdot 8$ & & & & & rainfall. \\
\hline Aug. 1 & $\cdot 390$ & $\cdot 140$ & $72 \cdot 2$ & & & & & \\
\hline 6 & $\cdot 373$ & $\cdot 123$ & $63 \cdot 4\}$ & 65 & $29 \cdot 9$ & S.W & & \\
\hline 9 & $\cdot 360$ & $\cdot 110$ & $56 \cdot 6$ & & & & & \\
\hline Mean & $\cdots$ & $\ldots$ & $57 \cdot 7$ & & & & & \\
\hline Oct. 17 & 419 & $\cdot 169$ & $87 \cdot 1$ & 51 & $30 \cdot 1$ & $\mathbf{S} \cdot \mathrm{W}$. & $\ldots$ & Antierclone. \\
\hline 24 & -331 & $\cdot 081$ & $4 i 7$ & 40 & $29 \cdot 9$ & $\mathrm{~W}$. & 12 & \\
\hline 31 & 361 & $\cdot 111$ & $57 \cdot 3$ & 35 & $30 \cdot 2$ & N.W. & $\ldots$ & Anticjelone. \\
\hline Nov, 5 & -415 & $\cdot 165$ & $85 \cdot 1 ?$ & 40 & 296 & ... & 63 & \\
\hline 11 & $\cdot 420$ & $\cdot 170$ & $87 \cdot 6$ & 37 & $29 \cdot 8$ & W. & $\ldots$ & $\begin{array}{l}\text { Heavy rain pre- } \\
\text { riously. }\end{array}$ \\
\hline Mean & $\cdots$ & ... & $71 \cdot 9$ & & & & & \\
\hline
\end{tabular}

SERIES 2.

\begin{tabular}{|c|c|c|c|c|c|c|c|c|}
\hline $\begin{array}{c}1907 \\
\text { Dec. } 9\end{array}$ & $880 ?$ & $\cdot 43$ & $108 ?$ & 36 & $30 \cdot 0$ & S. & $\ldots$ & Thaw after frost \\
\hline 12 & $\cdot 617$ & $\cdot 167$ & 42 & 29 & $29 \cdot 6$ & W. & 0.5 & Cyclone, rain, \\
\hline 20 & 571 & $\cdot 123$ & 31 & 21 & $30 \cdot 0$ & W. & & \\
\hline 23 & $1 \cdot 24 ?$ & $\cdot 79$ & $198 ?$ & 30 & $30 \cdot 0$ & W. & 0.35 & \\
\hline 26 & 84 & $\cdot 39$ & 98 & 27 & $29 \cdot 7$ & $\mathrm{~S}$. & $\ldots$ & Cyclone, \\
\hline Mean & $\ldots$ & $\ldots$ & $95 \cdot 2$ & & & & & \\
\hline
\end{tabular}


Emanation in the Atmosphere near Earth's Surface. $\quad 629$

SERIES 2 (continued).

\begin{tabular}{|c|c|c|c|c|c|c|c|c|}
\hline Date. & $\begin{array}{l}\text { Electro- } \\
\text { scope } \\
\text { reading. }\end{array}$ & $\begin{array}{l}\text { Less } \\
\text { "rest" } \\
\text { ralue. }\end{array}$ & $\underset{\text { Rrms. } \times 10-12}{\mid}$ & $\begin{array}{l}\text { Temp. } \\
\text { Fahr. }\end{array}$ & $\begin{array}{l}\text { Bar. } \\
\text { ins. }\end{array}$ & Wind. & $\begin{array}{c}\text { Rain } \\
\text { ins. }\end{array}$ & Remarks. \\
\hline $\begin{array}{r}1908 \\
\text { Jan. } 2 \\
6\end{array}$ & $\begin{array}{l}\cdot 726 \\
.60\end{array}$ & $\begin{array}{l}276 \\
\cdot 150\end{array}$ & $\begin{array}{l}69 \cdot 3 \\
37 \cdot 6\end{array}$ & $\begin{array}{l}13 \\
16\end{array}$ & $\begin{array}{l}30 \cdot 0 \\
29 \cdot 8\end{array}$ & $\begin{array}{l}\text { W. } \\
\text { s.W. }\end{array}$ & $\begin{array}{l}03 \\
\ldots\end{array}$ & $\begin{array}{l}\text { Thaw on 30th } \\
\text { Dee. } \\
\text { A cold spell. }\end{array}$ \\
\hline 9 & 877 & 427 & $10 \overline{7} \cdot 0$ & 24 & $29 \cdot 5$ & S.W. & $\ldots$ & $\begin{array}{l}8 \text { ins. snowfall. } \\
20 \text { ins, on ground. }\end{array}$ \\
\hline 13 & 583 & $\cdot 133$ & $33 \div 4$ & 17 & $29 \cdot 7$ & N.E. & & \\
\hline 16 & $\cdot 688$ & $\cdot 238$ & 604 & 6 & $29 \cdot 9$ & N.W. & $\cdots$ & Cold spell. \\
\hline 20 & $54 t$ & .094 & 248 & 11 & $30 \cdot 1$ & & & \\
\hline 23 & 858 & 408 & $102 \cdot 4$ & 31 & $29 \cdot 9$ & W. & $0 \cdot 34$ & $\begin{array}{l}\text { Well marked } \\
\text { thaw. }\end{array}$ \\
\hline 27 & 750 & $\cdot 300$ & $75 \cdot 4$ & 13 & $29 \cdot 5$ & N.E. & & \\
\hline 30 & .509 & $\cdot 059$ & $14 \cdot 7$ & -4 & $30 \cdot 3$ & W. & $\cdots$ & Very cold spell, \\
\hline Mean & .. & $\ldots$ & $58 \cdot 2$ & & & & & \\
\hline Mar. 10 & .524 & .074 & $18 \cdot 5$ & 21 & $30 \cdot 3$ & W. & ... & $\begin{array}{l}2 \frac{1}{2} \mathrm{ft} \text {. suow on } \\
\text { ground. }\end{array}$ \\
\hline 13 & $\cdot 611$ & $\cdot 161$ & $40 \cdot 1$ & 27 & $29 \cdot 9$ & & & \\
\hline 16 & $\cdot 712$ & .262 & $65 \cdot 5$ & 24 & $29 \cdot 6$ & S.W. & 09 & Thaw. \\
\hline 19 & 625 & $\cdot 175$ & $43 \cdot 8$ & 15 & $30 \cdot 0$ & E. & & \\
\hline 23 & 710 & .260 & $65 \cdot 2$ & 29 & $29 \cdot 9$ & W. & $0 \cdot 16$ & * \\
\hline 26 & 618 & $\cdot 168$ & $42 \cdot 2$ & 29 & $29 \cdot 9$ & W. & $0 \cdot 21$ & \\
\hline 31 & .621 & 171 & 429 & 32 & $30 \cdot 0$ & W. & $\cdots$ & $1 \mathrm{ft}$. snow on \\
\hline Mean & $\ldots$ & $\cdots$ & $45 \cdot 5$ & & & & & \\
\hline Apr. 3 & .582 & $\cdot 132$ & $33 \cdot 2$ & 25 & $29 \cdot 7$ & W. & 0.02 & $\begin{array}{l}1 \mathrm{ft} \text {. snow on } \\
\text { ground. }\end{array}$ \\
\hline 6 & 591 & $\cdot 144$ & $39 \cdot 9$ & 29 & $30 \cdot 0$ & W. & $0 \cdot 1$ & \\
\hline 9 & $\cdot 678$ & .228 & $57 \cdot 3$ & 32 & $30 \cdot 0$ & E. & $0 \cdot 3$ & \\
\hline 13 & .560 & $\cdot 110$ & $31 \cdot 3$ & 35 & 297 & W. & & \\
\hline 16 & 627 & $\cdot 177$ & $37 \cdot 0$ & 32 & $30 \cdot 2$ & S.W. & $\ldots$ & $\underset{\text { Snow nearly }}{\text { gone. }}$ \\
\hline 20 & 610 & $\cdot 160$ & $40 \cdot 2$ & 35 & $29 \cdot 6$ & S.W. & $0 \cdot 2$ & \\
\hline 23 & $\cdot 684$ & 234 & $58 \cdot 6$ & 38 & $29 \cdot 8$ & w. & & \\
\hline 27 & 821 & 371 & 930 & 53 & 297 & S.E. & $1 \cdot 0$ & $\begin{array}{l}\text { Thaw, rain, } \\
\text { cyclone. }\end{array}$ \\
\hline 30 & $\cdot 745$ & 295 & $74 \cdot 1$ & 46 & $29 \cdot \mathrm{S}$ & s.W. & $0 \cdot 1$ & \\
\hline Mean & $\cdots$ & $\cdots$ & $51 \cdot 5$ & & & & & \\
\hline
\end{tabular}

Mean of monthly Means .. 59.7 * During March and early April thaw and frost alternated. Snow went mainly by evaporation. 
The best examples of cyclone effects were

$\begin{array}{ccc}9 \text { Dec. 1907. } & 108 ? & \text { grm. } \times 10^{-12} \\ 23 \text { J" } & 198 ? & " \\ 23 \text { Jan. 1908. } & 102 & " \\ 27 \text { April ," } & 93 & "\end{array}$

and of anticyclones

$\begin{array}{lrc}20 \text { Dec. 1907. } & 31 & \text { grm. } \times 10^{-12} \\ 20 \text { Jan. } 1908 . & 25 & " \\ \text { 30 Jan. }, & 15 & " \\ \text { 10 March" } & 19 & "\end{array}$

On 30th January the barometer rose to 30.5 , and the thermometer fell to $20^{\circ}$ below zero, Fahr. The natural leak of the electroscope, and the "rest" experiments, were not affected by the changes of weather, as the laboratory was dry and at a steady temperature.

The reading of $23 \mathrm{rd}$ December was nearly twice as great as any other, and may perhaps have been incorrect. Excepting this, the ratio of the greatest to the least values was 7 to 1 , and this is less than the corresponding ratio 16 to 1 , found by Elster and Geitel in the case of the active deposit collected from the atmosphere by a negatively charged wire. The variations in the amount of active deposit are modified by the influence of smoke, dust, and mist-disturbing factors which are avoided in measurement of the emanation.

There are many reasons why the amount of radium emanation in the atmosphere shonld be increased when a cyclone prevails, for then :-

(1) The air is moving along the surface of the earth in large spiral paths towards the centre of the depression where the air rises. Thus the air near the earth's surface contains much of the emanation escaping from the ground. But with an anticyclone, air is descending from altitudes where the contained emanation has decayed, and where fresh supplies are not forthcoming.

(2) Diminishing pressure causes radium emanation, with other gases, to pass out from the ground into the atmosphere.

(3) Rain usually accompanies a cyclone, and in winter higher temperatures prevail and cause the snow to melt. In both cases water enters and moistens the soil, and emanation escapes more readily from radium salts when these are moist or in solution.

After experimenting for some months it was found possible 
to make fairly good forecasts of the radium equivalent, when weather of a pronounced type prevailed. The gradual thaw of March and April produced fairly steady values, until the well-defined cyclone of 27 th April arrived from the westward with a south wind and an inch of rainfall, and then there was a considerable increase.

The month of February was spent in calibrating instruments, and in vain endeavours to obtain daily measurements. The quantity of emanation collected between 5 P.M. and 9 A.M. proved too small for measurement with any approach to accuracy.

The mean of the results is $59 \cdot 7 \times 10^{-12} \mathrm{grm}$. of radium as the amount in equilibrium with the emanation present in a cubic ruetre of air. This is in fair agreement with the determination $82 \times 10^{-12}$ described in a previous paper ( $P$ hil. Mag. July 1905). In the latter case, the active deposit on a negatively charged wire was measured and compared with similar deposits from the emanation arising from a standard solution.

I regret that pressure of other work prevented me from making simultaneous observations on the active deposit, ionization and potential gradient. At present there is much waste of labour in the incomplete work of many observers who have not time or opportunity to make more thorough investigations. The time bas certainly come for a complete radioactive survey at a well-equipped laboratory with a sufficient staff of skilled observers. Simultaneous and continuous experiments are needed on the meteorological conditions, amount of radium emanation in the atmosphere, active deposit obtainable, potential gradient, penetrating radiation, and ionization (Ebert's and Langevin's methods). In the measurement of penetrating radiation too much reliance has sometimes been placed on the readings of a single instrument. It is desirable to observe the fluctuations with both electroscope and electrometer, and to ascertain if the variations agree with different types and arrangements of apparatus.

Those engaged in balloon, or kite, experiments might obtain useful information on the penetrating radiation at high altitudes, by observations on the rate of discharge of electroscopes at the earth's surface and at considerable elevation. The active deposit on the wires employed should also be measured.

The ionization of the atmosphere near the ground appears to be largely due to radioactive matter, and meteorological conditions are dependent on ionization to a large and unknown 
extent, so that a thorough radioactive survey cannot fail to be of interest and advantage.

\section{Summary.}

(1) The amount of radium which would be in equilibrium with the average amount of radium emanation present in a cubic metre of air, as measured at Montreal at intervals extending over a year, 1907-8, is $60 \times 10^{-12}$ gram.

(2) The amount of radium emanation in the atmosphere varied so that the maximum is to the minimum as about 7 is to 1 .

(3) The amounts in summer and in winter are not widely different, and large changes of temperature appear to have little or no direct influence on the quantity.

(4) The approach of a deep cyclone, accompanied by heavy rain or a quick thaw of snow, cause an increase, whilst anticyclonic conditions, with dry or very cold weather, give a decrease of the radium emanation in the air.

I am grateful to Professor Rutherford for proposing to me this experimental work and for suggesting the general methods adopted.

Hornsea, 27 th June, 1908.

\section{The Relation between Uranium and Radium. III.*} By Fredkrick Soddy, M.A.广

MORE than a year has elapsed since the last published 1 tests in the second series of experiments with large quantities of uranium, purified with great care by $\mathrm{Mr}$. T. D. Mackenzie. The subsequent tests on these preparations and some new experiments are given in the present paper. The only change of method to be recorded is the use of a glass electroscope of globular form, silvered internally, which being air-tight and capable of standing a vacuum, is more suited for the measurement of minute quantities of radium emanation, as the observations can be extended over longer intervals without fear of loss. In Experiments I. and II. the emanation has been extracted by the mercury pump exactly as before; but this arrangement has now been dispensed with and the solutions sealed up in large flasks. Subsequent

* I. Soddy, Phil. Mag. June 1905, p. 768. II. Soddy and Mackenzie, Phil. Mag. Aug. 1907, p. 272.

t Communicated by the Althor. 